\title{
Determination of Nonmetallic Inclusions in the Rimmed Steel Ingot with X-Ray Microanalyzer*
}

\author{
By Minoru Sasaki,** Tomoo Takahari,** and Hiroki Hamada**
}

\begin{abstract}
Synopsis
For investigating the mineral composition and microstructure of nonmetallic inclusion in the rimmed steel ingot, $X$-ray microanalysis and optical microscopic observation were performed on the polished thin section of the specimen taken from the ingot. Minerals found in the inclusions were $(\mathrm{Mn}, \mathrm{Fe}) \mathrm{O}$, (Mn, Fe)S, tephroite, spessartite, and galaxite. All the inclusions examined are classified into three types by the main composing minerals, i.e., (a) oxide, (b) oxide and silicate, and (c) oxide, silicate, and aluminate. The structure of inclusion is discussed in relation to the crystallization and precipitation process of crystals from the melt of the mixture of $\mathrm{MnO}$, $\mathrm{FeO}, \mathrm{Al}_{2} \mathrm{O}_{3}, \mathrm{SiO}_{2}$, and $\mathrm{S}$. The inhomogeneous phase of the inclusions were analyzed with an $X$-ray microanalyzer, but the sum total of the analytical values deviated considerably from $100 \%$ in many cases. This deviation is explained to be originated in the $X$-ray generation mechanism in the inhomogeneous phase and in the insufficient correction of the detected $X$-ray intensity.
\end{abstract}

\section{Introduction}

Nonmetallic inclusions in steel ingots or rolled materials generally consist of several sorts of fine minerals. $\mathrm{X}$-ray microanalysis is an effective method for determining inclusions. ${ }^{1)}$ It is necessary, however, that for the accurate analysis the homogeneous part which is larger than the area effectively excited by an electron beam is required to be selected in the inclusion. Usually, this is very difficult.

The polished thin section method was developed by the authors ${ }^{2)}$ for the mineralogical investigation of the sample whose structure is complicated such as the nonmetallic inclusion. In this study on the inclusions in the rimmed steel ingots this method was applied for selecting the homogeneous part, and satisfactory analytical results were obtained. Moreover, with the results of both X-ray microanalysis and optical observation, the mineral composition and the microscopic structure of the inclusions were exactly determined.

In this paper, these results and the discussion on the problem of X-ray microanalysis of the inhomogeneous phase are described.

\section{Experimental Method}

1. Samples and Polished Thin Sections

Specimens examined were taken from the center of the bottom of 12-t ingots of rimmed steel. The chemical compositions of the ingots are shown in Table 1. Small pieces of about $10 \times 10 \times 1 \mathrm{~m} / \mathrm{m}$ were cut from the specimens. One side of the plate was lapped and stuck on a slide glass. The stuck piece was polished to about $10 \mu$ in thickness with emery paper and mirrorfinished. The outline of this technique is illustrated in Fig. 1.
The microscopic structure of the inclusion in the polished thin section was observed with both reflection and transmission lights under optical microscope. Then, the homogeneous parts of each mineral of the inclusion were selected.

\section{X-Ray Microanalysis}

The polished thin section which carbon was deposited on the surface was used for the analysis.

Point analysis was made for manganese and iron at $30 \mathrm{kV}$ of acceleration voltage, and for lighter elements than calcium at $15 \mathrm{kV}$.

Inhomogeneous phases were analyzed with X-ray microanalyzer under the various conditions of the accelerating voltage, electron beam size, and sample current.

Philibert's ${ }^{3)}$ and Modified Castaing's formulas ${ }^{4)}$ were used to correct experimental values for absorption and

Table 1. Chemical composition of ingot samples

\begin{tabular}{c|ccccc} 
Sample & C & Mn & S & O & P \\
\hline I & 0.085 & 0.42 & 0.016 & 0.043 & 0.018 \\
II & 0.060 & 0.32 & 0.017 & 0.075 & 0.013
\end{tabular}
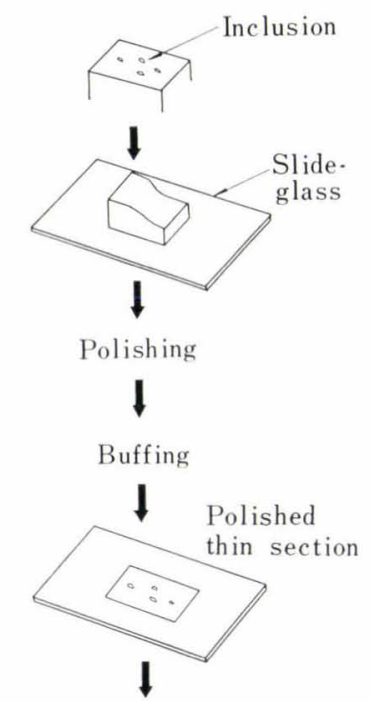

Polarization microscope

Analysis with

X-ray microanalyzer

Fig. 1. Preparation method for polished thin section of steel material

* Presented at the 72nd ISIJ Meeting, October, 1966 in Amagasaki. Manuscript received January 17, 1968.

** Tokyo Research Institute, Yawata Iron \& Steel Co., Ltd., Ida, Kawasaki 211. 
fluorescence enhancement effects, respectively.

\section{Results and Discussion}

All the inclusions in the sample were classified into the following three types :

i. Inclusions main mineral of which is $\mathrm{MnO}-\mathrm{FeO}$ solid solution, abbreviated to $(\mathrm{Mn}, \mathrm{Fe}) \mathrm{O}$,

ii. Inclusions which contain much of silicate, and

iii. Inclusions which contain galaxite.

\section{Inclusions Main Mineral of Which is (Mn, Fe)O}

\section{Inclusion Tentatively Named $A^{*}$}

The inclusions of this type were found all over the specimens. Most of them were finer than 20 to $30 \mu$ in size.

As shown in Photo. 1 (a) they consist of the spherical gray mineral surrounded by the fine particles. The inclusion on the right side is transparent, while that on the left side is opaque. In spite of $10 \mu$ in thickness of the section the iron matrix remains beneath the latter.

The gray mineral is optically isotropic and its trans-

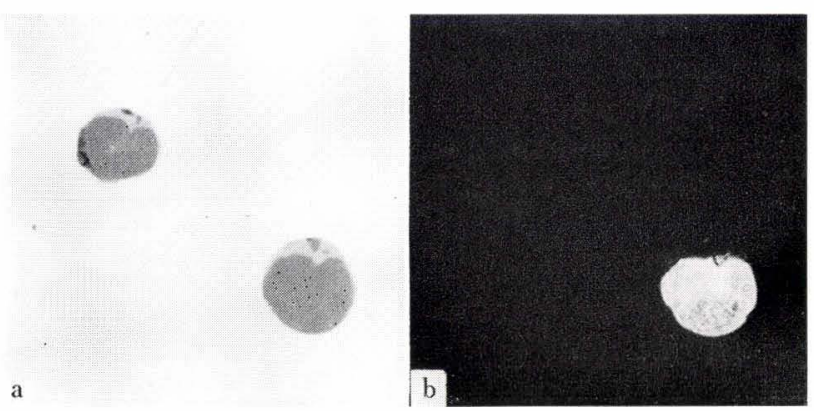

Photo. 1. Microstructure of an inclusions tentatively named $A$ $(\times 800)(1 / 2)$

$$
\text { a : reflection }
$$

b : transmission mission color is yellow. From these characteristics it is identified ( $\mathrm{Mn}, \mathrm{Fe}) \mathrm{O}$.

The result of quantitative analysis with X-ray microanalyzer is indicated in Table 2. The gray mineral of the inclusion on the right side of Photo. 1 (a) shows the satisfactory analytical result. While, the sum total of the percentage of the composition of the gray mineral of the left one is far over $100 \%$. It suggests that the value from the iron matrix beneath the inclusion was included.

The scanning images of characteristic X-ray are shown in Photo. 2. These photographs indicate that

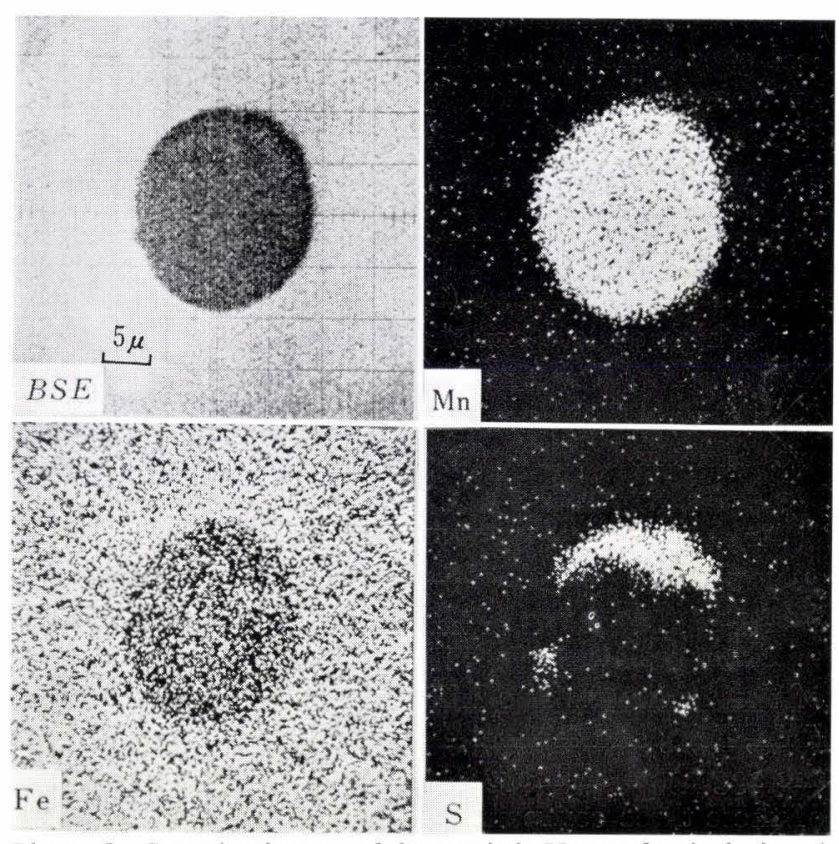

Photo. 2. Scanning images of charateristic X-ray of an inclusion $A$ $B S E$ : back scattered electron image

Table 2. Results of X-ray microanalysis of the inclusions

\begin{tabular}{|c|c|c|c|c|c|c|c|c|c|}
\hline \multirow{2}{*}{ Inclusion } & \multirow{2}{*}{$\begin{array}{l}\text { Ingot } \\
\text { No. }\end{array}$} & \multicolumn{2}{|c|}{ Analyzed part } & \multicolumn{6}{|c|}{ As oxide and sulfur } \\
\hline & & Ciolor & $\begin{array}{c}\text { Homogeneity } \\
\text { of phase }\end{array}$ & $\mathrm{MnO} * *$ & $\mathrm{FeO}$ & $\mathrm{Al}_{2} \mathrm{O}_{3}$ & $\mathrm{SiO}_{2}$ & $\mathrm{~S}$ & Sum*** \\
\hline \multirow{2}{*}{$\begin{array}{l}A-a \\
A-b\end{array}$} & \multirow{2}{*}{ II } & Gray & Hom* & 72 & 29 & - & - & - & 101 \\
\hline & & Gray & Hom & 65 & 43 & - & - & - & 108 \\
\hline \multirow[t]{2}{*}{$B$} & \multirow[t]{2}{*}{ I } & Gray & Hom & 77 & 24 & - & - & - & 101 \\
\hline & & (Aggregate) & Inhom* & 76 & 11 & & 13 & 1.0 & 101 \\
\hline$C$ & II & (Aggregate) & Inhom & 72 & 13 & 3.8 & 7.8 & 1.8 & 98 \\
\hline \multirow[t]{3}{*}{$D$} & \multirow[t]{3}{*}{ II } & Gray & Hom & 68 & 25 & $\operatorname{tr}$ & - & 1.5 & 94 \\
\hline & & Dark gray & Hom & 65 & 20 & 2.4 & 17 & - & 104 \\
\hline & & (Aggregate) & Inhom & 60 & 16 & 4.3 & 12 & 1.0 & 93 \\
\hline$E$ & I & (Aggregate) & Inhom & 53 & 12 & 6.0 & 9.9 & - & 81 \\
\hline \multirow[t]{2}{*}{$F$} & \multirow[t]{2}{*}{ I } & $\begin{array}{l}\text { Dark gray } \\
\text { (Aggregate) }\end{array}$ & Inhom & 56 & 14 & 11 & 10 & - & 91 \\
\hline & & $\begin{array}{l}\text { Gray } \\
\text { (Aggregate) }\end{array}$ & Inhom & 58 & 16 & 8.2 & - & 12 & 88 \\
\hline
\end{tabular}

\footnotetext{
* Hom : homogeneous

Inhom : inhomogeneous

** The detected manganese content was converted to the value of $\mathrm{MnO}(\%)$ without taking into consideration of $\mathrm{MnS}$.

*** Sum $=$ oxides $(\%)+\operatorname{sulfur}(\%) \cdot\left(A_{s}-A_{o}\right) / A_{s},(A:$ atomic weight $)$
} 
the complicated phase around the large spheres of $(\mathrm{Mn}, \mathrm{Fe}) \mathrm{O}$ consists of the fine particles of $(\mathrm{Mn}, \mathrm{Fe}) \mathrm{O}$ and $(\mathrm{Mn}, \mathrm{Fe}) \mathrm{S}$.

From the above discussions, the microstructure of the inclusion is considered to be formed as follows: (Mn, Fe) O crystallizes primarily from the original melt of the inclusion. Then, the remainder melt solidifies around the primary crystals and forms the eutectic which consists of $(\mathrm{Mn}, \mathrm{Fe}) \mathrm{O}$ and $(\mathrm{Mn}, \mathrm{Fe}) \mathrm{S}$.

\section{Inclusion Tentatively Named $B$}

Though the inclusions of this type are similar to inclusion $A$, only two or three of them are found in a section of specimen.

As shown in Photo. 3, the inclusion consists of spherical gray mineral and the aggregate of fine particles by which the gap among the spheres of gray mineral is filled. Transmission color of the former is yellow and that of the latter reddish yellow. Moreover, the dark red mineral whose shape is like a grain of bean and optically anisotropic crystals are observed by transmission light (Photo. 3 (b), (c)). The latter mineral has a high optical double refraction and its shape is like a pillar. By the above optical observation the dark gray, dark red, and optically anisotropic minerals are identified with $(\mathrm{Mn}, \mathrm{Fe}) \mathrm{O},(\mathrm{Mn}, \mathrm{Fe}) \mathrm{S}$, and tephroite, respectively.

Each of the sum totals of the analytical values of the gray mineral and the aggregate* with $\mathrm{X}$-ray microanalyzer is close to $100 \%$ as shown in Table 2 .

From the above results, the crystallization process of these minerals is clarified as follows: ( $\mathrm{Mn}, \mathrm{Fe}) \mathrm{O}$, $(\mathrm{Mn}, \mathrm{Fe}) \mathrm{S}$, and tephroite are the primary crystals and the aggregate of fine particles is the eutectic consisting of these three components.

\section{Inclusions Containing Much Silicate}

The inclusions of this type are found all large, but the ratio of this type to all the inclusions that consisted mainly of (Mn, Fe)O was small. In this paragraph, two kinds of inclusions in which the particle size of silicate is different are mentioned.

\section{Inclusion Tentatively Named $\boldsymbol{C}$}

This is the aggregate of very fine particles the size of which is less than $1 \mu$ (Photo. 4). By reflection light dendritic gray and spherical light gray minerals were found. Then, yellow and dark red particles were observed by transmission light. Under crossed nicols a few of optically anisotropic crystals were noticed.

The sum total of the quantitative values of inclusion $C$ which is an inhomogeneous phase is close to $100 \%$ as well as in the case of the eutectic of inclusion $B$.

The mineral composition of this inclusion is determined with the aid of the optical characteristics, the result of $\mathrm{X}$-ray microanalysis, and the phase diagrams of the systems of $\mathrm{MnO}, \mathrm{FeO}, \mathrm{Al}_{2} \mathrm{O}_{3}, \mathrm{SiO}_{2}$, and sulfides.

In the system of $(\mathrm{Mn}, \mathrm{Fe}) \mathrm{O}-\mathrm{Al}_{2} \mathrm{O}_{3}-\mathrm{SiO}_{2}$, the dendritic gray mineral is $(\mathrm{Mn}, \mathrm{Fe}) \mathrm{O}$. The coexisting silicate mineral is expected to be spessartite and/or tephroite, as shown in Fig. ${ }^{51}$. The amount of the latter of inclusion $C$ is thought to be very small because optically anisotropic crystals are only a few. The light gray mineral as mentioned above is $(\mathrm{Mn}, \mathrm{Fe}) \mathrm{S}$. Consequently, (Mn, Fe) O, (Mn, Fe) S, and spessartite are primary crystals, and the eutectic is composed of fine particles of these three minerals and tephroite. Moreover, from the fact that the primary crystals (Mn, $\mathrm{Fe}) \mathrm{O}$ are fine and a few, the chemical composition of the original melt of inclusion $C$ is estimated to be nearly that of the eutectic composed of $(\mathrm{Mn}, \mathrm{Fe}) \mathrm{O}$, spessartite, and tephroite.

\section{Inclusion Tentatively Named $D$}

This is a kind of inclusion consisting of coarse crystals of silicate minerals as shown in Photo. 5. The outer shell of this inclusion consists of the gray mineral the size of which is about $10 \mu$ and the inner shell, the dark gray one. At the central part several sorts of fine minerals are aggregated.

The gray mineral at the outer shell is ( $\mathrm{Mn}, \mathrm{Fe}) \mathrm{O}$. Beneath it the sulfide was found with transmission light. The dark gray mineral has a high optical double refraction (Photo. $5(\mathrm{c})$ ). It is determined to be tephroite. Around this mineral fine particles of $(\mathrm{Mn}, \mathrm{Fe}) \mathrm{O}$ are observed. The homogeneous area of tephroite crystals is only 5 to $6 \mu$ in size.

By X-ray microanalysis of the gray mineral a little amount of sulphur is analyzed and the results are in-

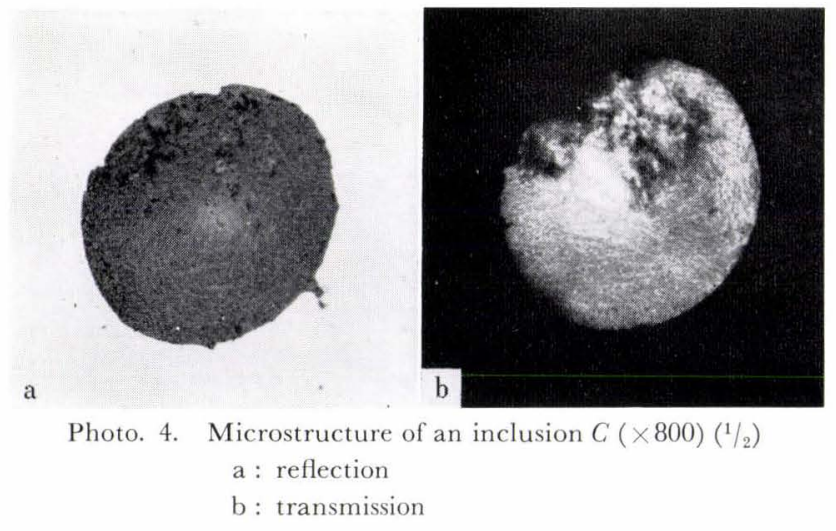

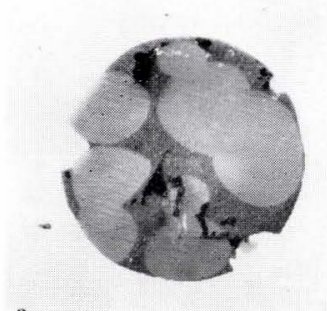

a

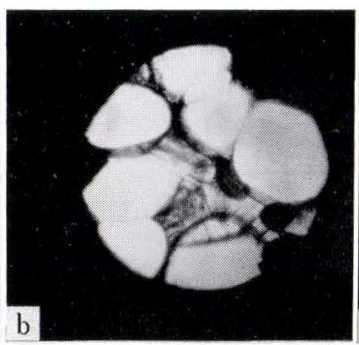

Photo. 3.

Microstructure of an inclusion $B(\times 800)(1 / 2)$

a : reflection

b : transmission

c : transmission (crossed nicols)

* In the analysis of the aggregate, the part at which the bean- and pilar-like crystals were embedded were avoided. 
dicated in Table 2. This shows that when the electron beam was bombarded on the gray mineral, the sulfide which existed beneath it was excited at the same time. While, the sum total of the quantitative values of the dark gray mineral is $104 \%$. This value is seemed to be reliable. However, the analytical values, 85\%( $\mathrm{Mn}, \mathrm{Fe}) \mathrm{O}$ and $17 \% \mathrm{SiO}_{2}$, do not agree with the theoretical composition of tephroite $(70.2 \% \mathrm{MnO}$ and $\left.29.8 \% \mathrm{SiO}_{2}\right)$. The difference between the observed and theoretical values are very large. This is caused by the simultaneous excitation of $(\mathrm{Mn}, \mathrm{Fe}) \mathrm{O}$ with tephroite by electrons. Thus, the great care should be taken in examining the analytical value with $\mathrm{X}$-ray microanalyzer.

From the above results the microstructure of inclusion $D$ is considered to be formed by the following process: ( $\mathrm{Mn}, \mathrm{Fe}) \mathrm{O}$ crystallizes primarily along the contact area with molten steel, then, the crystallization of $(\mathrm{Mn}, \mathrm{Fe}) \mathrm{S}$ and tephroite follow, and finally, the eutectic which consists of spessartite and the abovementioned three sorts of minerals is formed.

\section{Inclusions Containing Galaxite}

\section{Inclusion Tentatively Named $E$}

The inclusions of this kind are large, but rarely found.

As shown in Photo. 6, dendritic and fine granular gray minerals are found in the dark gray matrix. With a reflection light yellow and yellowish crystals 2 to $3 \mu$ in diameter) in aggregation were observed and optically anisotropic crystals were not found.

The reproducibility of the analytical values with

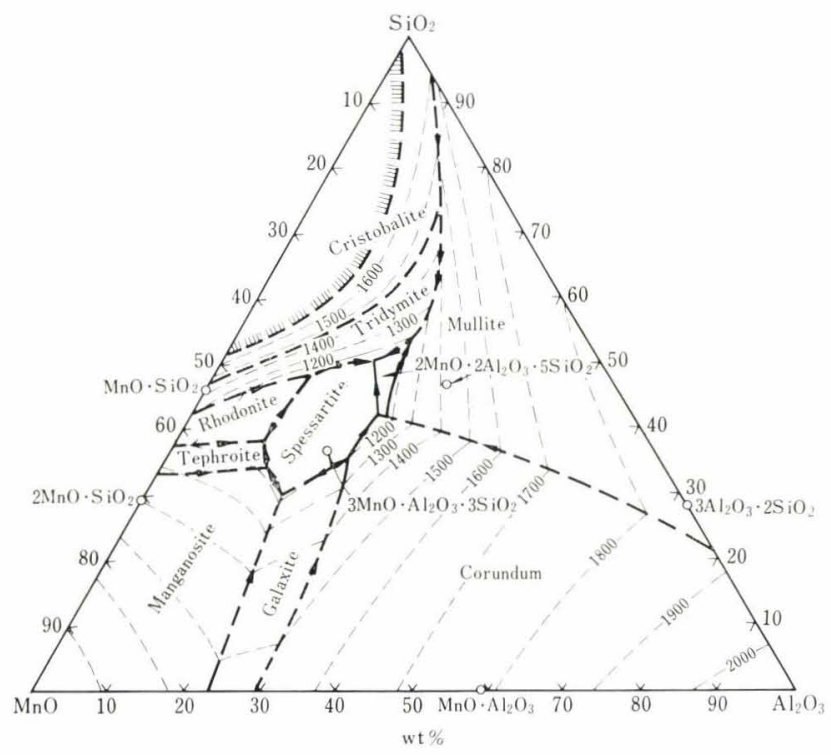

Fig. 2. Phase diagram of the system of $\mathrm{MnO}-\mathrm{Al}_{2} \mathrm{O}_{3}-\mathrm{SiO}_{2}{ }^{5)}$
X-ray microanalyzer was very statisfactory, while the sum total of the quantitative values was only $82 \%$ (Table 2). The reasons are discussed in the following paragraph.

The minerals of this inclusion are identified with ( $\mathrm{Mn}, \mathrm{Fe}$ ) O, galaxite, and spessartite, because all of crystals contained in the inclusion are optically isotropic. The dendritic crystal of $(\mathrm{Mn}, \mathrm{Fe}) \mathrm{O}$ is very fine but not so many. The composition of the original melt of inclusion $E$ is estimated to be close to that of the eutectic of galaxite and spessartite in the $(\mathrm{Mn}, \mathrm{Fe}) \mathrm{O}-\mathrm{Al}_{2} \mathrm{O}_{3}-\mathrm{SiO}_{2}$ system.

\section{Inclusion Tentatively Named $\boldsymbol{F}$}

This inclusion, as shown in Photo. 7, consists of three parts. They are :

i. coarse particles of dark gray mineral at the left side,

ii. the aggregate of coarse particles of gray and light gray minerals and fine ones of dark gray mineral at the middle part, and

iii. the aggregate of fine particles of gray and dark gray minerals at the right side.

The coarse dark gray mineral is optically isotropic and

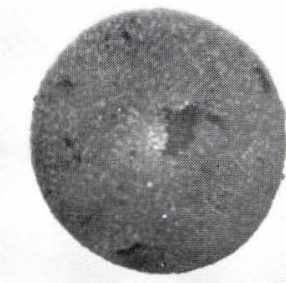

a

Photo. 6. Microstructure of an inclusion $E(\times 800)(1 / 2)$ a : reflection $\mathrm{b}:$ transmission
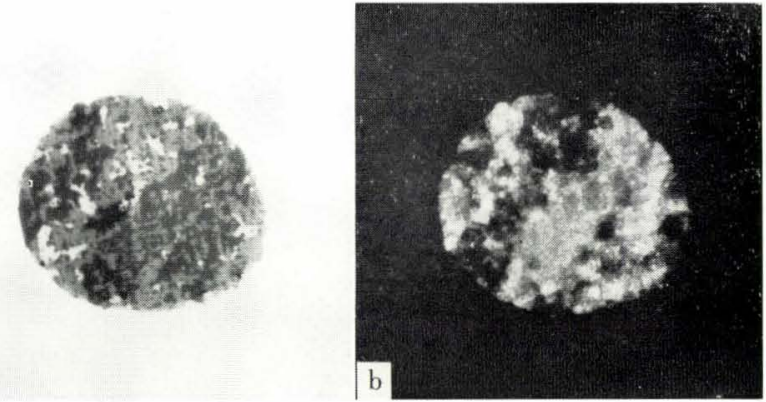

Photo. 7. Microstructure of an inclusion $F(\times 800)(1 / 2)$ a : reflection b : transmission
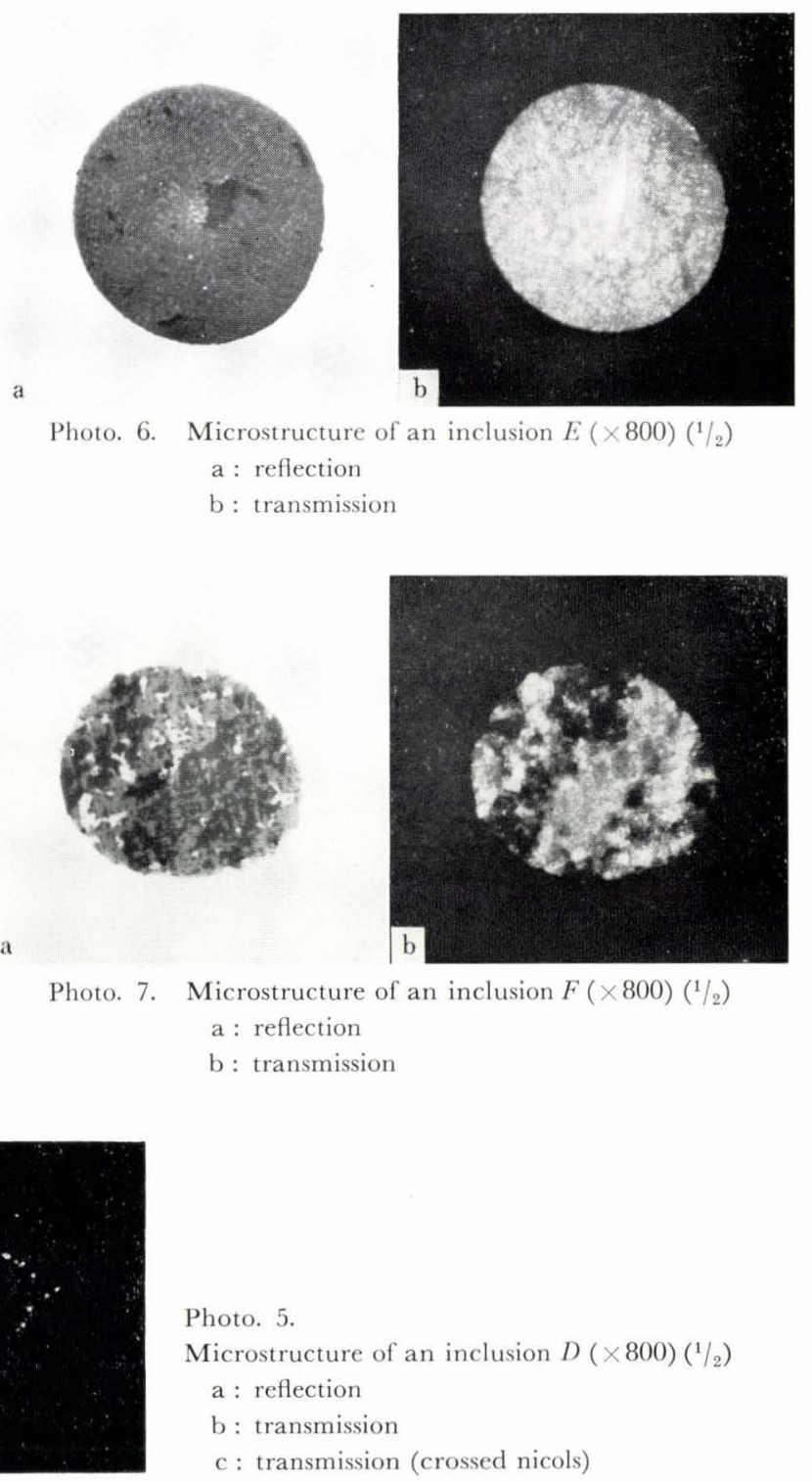

Photo. 5.

Microstructure of an inclusion $D(\times 800)(1 / 2)$

a : reflection

$\mathrm{b}:$ transmission

c : transmission (crossed nicols)

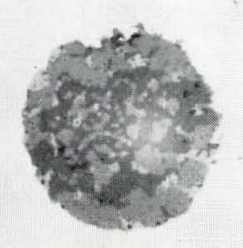

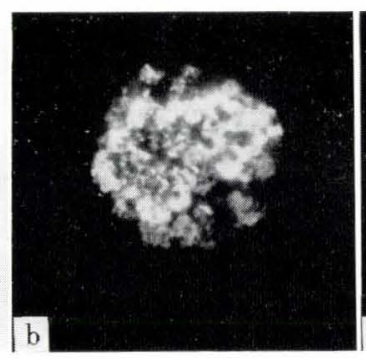

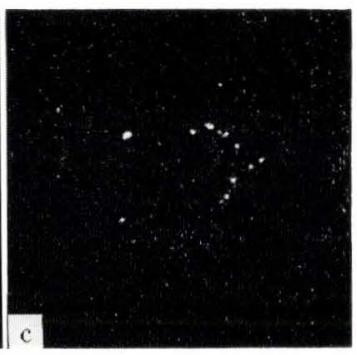


it is assumed to be either spessartite or galaxite. At the middle part $(\mathrm{Mn}, \mathrm{Fe}) \mathrm{O}$ and $(\mathrm{Mn}, \mathrm{Fe}) \mathrm{S}$ were observed with transmission light. Moreover, fine crystals of yellow and colorless minerals which were optically isotropic were found at the right side. The former is $(\mathrm{Mn}, \mathrm{Fe}) \mathrm{O}$ and the latter is either spessartite or galaxite.

The sum total of the analytical values of the aggregate of fine particles is $91 \%$ and that of coarse particles is only $88 \%$.

The scanning images of the main elements of inclusion $F$ are shown in Photo. 8. The distributions of $\mathrm{Mn}, \mathrm{Fe}$, and $\mathrm{Al}$ are nearly uniform throughout the inclusion, while that of $\mathrm{Si}$ corresponds to the distribution of the coarse dark gray mineral and the aggregate of fine particles.

From the above results, the coarse dark gray mineral and the fine dark gray one in the middle part are identified spessartite and galaxite, respectively. The crystallization process of the minerals of inclusion $F$ is assumed as follows: Coarse particles of spessartite are primarily segregated and then the aggregate of fine particles of spessarite and $(\mathrm{Mn}, \mathrm{Fe}) \mathrm{O}$ is precipitated as shown at the right side of the inclusion in Photo. 7. From the remainder liquid, (Mn, Fe)S crystallizes together with the above minerals. The eutectic, which is formed finally, is composed of $(\mathrm{Mn}, \mathrm{Fe}) \mathrm{O}$, galaxite, and $(\mathrm{Mn}, \mathrm{Fe}) \mathrm{S}$.

4. Discussion on X-Ray Microanalytical Result of the Inhomogeneous Phase Composed of Several Sorts of Fine Minerals

Inhomogeneous parts of inclusion $E$ and $F$ were analyzed under various conditions. The results are listed in Table 3. There are not many differences among the analytical values of each phase. Therefore, the fine particles at the inhomogeneous part are estimated to be mixed homogeneously.

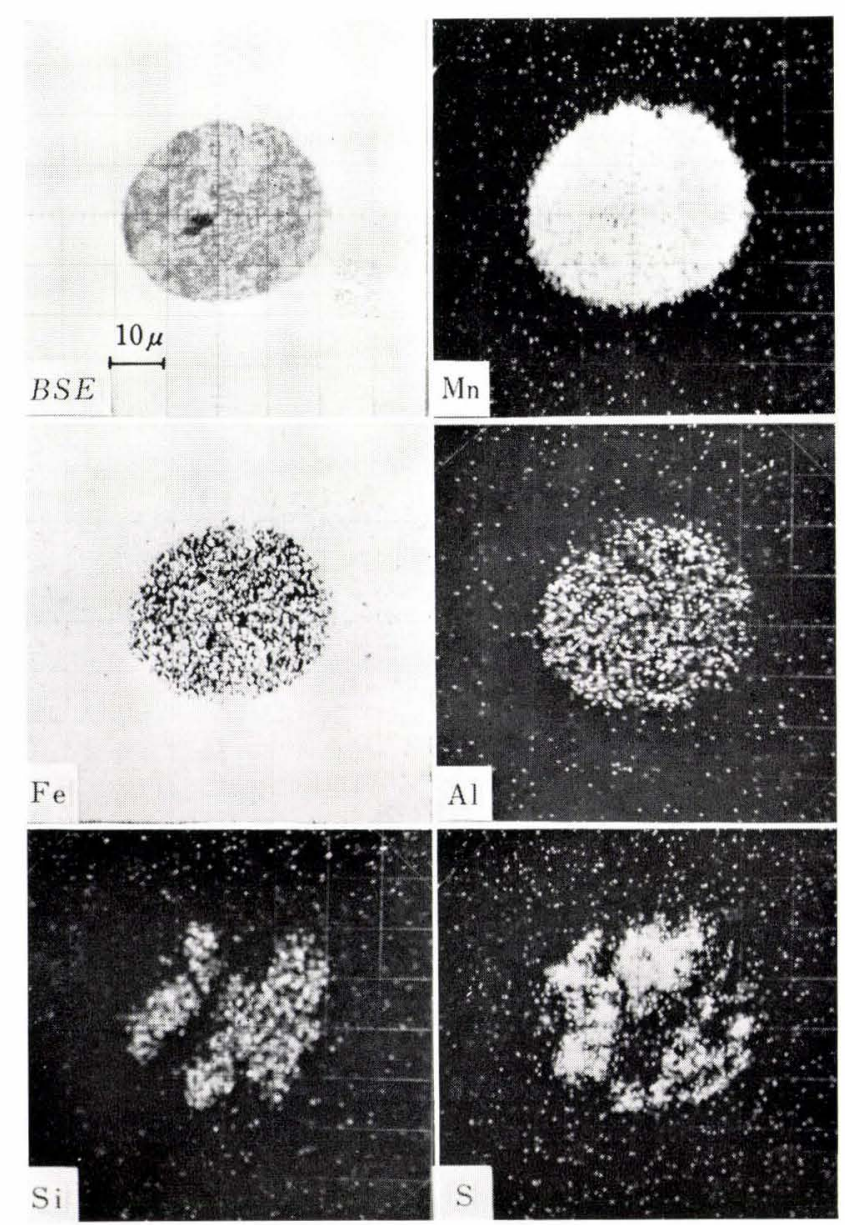

Photo. 8. Scanning images of characteristic X-ray of an inclu$\operatorname{sion} F$

$B S E$ : back scattered electron image

Table 3. Determined values of the inhomogeneous phases under various analytical conditions

\begin{tabular}{|c|c|c|c|c|c|c|}
\hline & Element & $\begin{array}{l}\text { Analytical } \\
\text { method }\end{array}$ & $\begin{array}{l}\text { Acceleration } \\
\text { voltage }(\mathrm{kV})\end{array}$ & $\begin{array}{l}\text { Spot size } \\
(\mu)\end{array}$ & $\begin{array}{l}\text { Sample current } \\
(\mu A)^{* * *}\end{array}$ & $\begin{array}{c}\text { Relative } \\
\text { intensity }(\%)\end{array}$ \\
\hline \multirow{10}{*}{$\begin{array}{c}\text { Inclusion } \\
E\end{array}$} & \multirow[t]{2}{*}{$\mathrm{Mn}$} & Scanning* & 30 & $2.5 \times 2.5$ & 0.007 & 40.0 \\
\hline & & Point** & , & ", & 0.016 & 39.5 \\
\hline & \multirow[t]{2}{*}{$\mathrm{Fe}$} & Scanning & , & , & 0.007 & 9.02 \\
\hline & & Point & , & , & 0.016 & 9.11 \\
\hline & \multirow[t]{2}{*}{$\mathrm{Al}$} & Scanning & " & ", & 0.010 & 1.34 \\
\hline & & Point & ", & , & 0.016 & 1.52 \\
\hline & \multirow{4}{*}{$\mathrm{Si}$} & $"$ & , & $5.0 \times 5.0$ & 0.016 & 1.53 \\
\hline & & Scanning & , & $2.5 \times 2.5$ & 0.010 & 2.98 \\
\hline & & Point & " & ", & 0.016 & 2.51 \\
\hline & & $"$ & $"$ & $5.0 \times 5.0$ & 0.016 & 2.54 \\
\hline \multirow{4}{*}{$\begin{array}{c}\text { Inclusion } \\
F \\
\text { (Dark gray part) }\end{array}$} & $\mathrm{Al}$ & Scanning & 15 & $2.5 \times 2.5$ & 0.022 & 4.93 \\
\hline & \multirow{3}{*}{$\mathrm{Si}$} & Point & , & $3.5 \times 5.0$ & 0.017 & 4.07 \\
\hline & & Scanning & , & $2.5 \times 2.5$ & 0.021 & 4.02 \\
\hline & & Point & $"$ & $4.0 \times 5.5$ & 0.019 & 3.60 \\
\hline \multirow{2}{*}{$\begin{array}{l}\text { Inclusion } \\
\qquad F \\
\text { (Gray part) }\end{array}$} & \multirow[t]{2}{*}{$\mathrm{Al}$} & Scanning & $"$ & $2.5 \times 2.5$ & 0.022 & 3.41 \\
\hline & & Point & " & $3.5 \times 5.0$ & 0.017 & 3.10 \\
\hline
\end{tabular}

* Scanning distance: about $10 \mu$

** Analyzed position: 3 to 5 points

*** Measured on brass 
In spite of this homogeneity, the sum total of values converted in terms of oxides is smaller than $100 \%$. This negative deviation is thought to be originated in the complex mechanism of X-ray generation in inhomogeneous phase.

As well known, the effective penetration depth $\left(Z_{m}\right)$ of the electrons under a constant accelerating voltage depends on density $(\rho)$, atomic weight $(A)$, and atomic number $(Z)$ of a sample material to be examined.

$$
Z_{m} \propto A / \rho Z
$$

Minerals contained in the inclusion $E$ and $F$ are (Mn, $\mathrm{Fe}) \mathrm{O},(\mathrm{Mn}, \mathrm{Fe}) \mathrm{S}$, tephroite, spessartite, and galaxite, and the densities $\left(\mathrm{g} / \mathrm{cm}^{3}\right)$ of these minerals are 5.36, $4.0,4.2,4.18$, and $4.03^{6}$, respectively. $A / \rho Z$, where for $A$ and $Z$ the mean values are adopted, is calculated as 0.41 for $(\mathrm{Mn}, \mathrm{Fe}) \mathrm{O}, 0.54$ for $(\mathrm{Mn}, \mathrm{Fe}) \mathrm{S}, 0.51$ for tephroite, 0.50 for spessartite, and 0.53 for galaxite. The elements contained in the above minerals except ( $\mathrm{Mn}, \mathrm{Fe}$ ) O are preferentially excited. Consequently, the detected intensity of characteristic $\mathrm{X}$-rays generated in the inhomogeneous phase is probably weak for $\mathrm{Mn}$ and $\mathrm{Fe}$ and strong for $\mathrm{Al}$ and $\mathrm{Si}$, comparing with those in the case that all the elements form a homogeneous phase. Moreover, when the absorption correction is applied for experimental values assuming that the analyzed phase is homogeneous, the calculated value seems to be considerably smaller for both $\mathrm{Al}$ and $\mathrm{Si}$ than the true value of the generated X-ray. It is thought that these two factors result the large negative deviation of values.

\section{Conclusion}

(1) The mineral composition and microstructure of nonmetallic inclusions in rimmed steel ingot were exactly determined by means of X-ray microanalysis and microscopic observation. Inclusions were clas- sified into three types by the mineral composition. The structure of the inclusions was discussed in relation to the crystallization and precipitation process of mineral phases from the original melt of inclusion.

(2) As to the inhomogeneous phase composed of several sorts of minerals which had different electron permeabilities, the sum total of the analytical values deviated remarkably from $100 \%$ in many cases. This deviation was assumed to be due to the insufficient correction of the detected intensity of characteristic X-ray the generation mechanism of which was different from that in the case of a homogeneous phase. While, in some cases, the total value was close to $100 \%$, but its reliability was thought to be not enough.

\section{Acknowledgements}

The authors thank Dr. S. Mizushima, the Director of Tokyo Research Institute, Yawata Iron and Steel Co., Ltd., for his interest in this research. They also gratefully acknowledge helpful discussions with Prof. H. Minato, The University of Tokyo and Prof. Y. Omori, Tohoku University.

\section{REFERENCES}

1) R. Kiessling and N. Lange: J. Iron Steel Inst., Special Report, 90 (1964); 100 (1966).

K. Sanbongi, Y. Omori, and I. Sawai: Tetsu-to-Hagané, 50 (1964), 1877.

2) M. Sasaki, R. Kusaka, and K. Arakawa: Tetsu-to-Hagané Overseas, 5 (1965) 324.

3) J. Philibert: X-Ray Optics and X-Ray Microanalysis, (1963), 379, Academic Press, New York.

4) K. Aoki and T. Sawatani: Yawata Technical Report, 255 (1966), 169.

5) R. B. Snow: J. Amer. Ceram. Soc., 20 (1943), 11.

6) A. N. Winchell: Microscopical Characters of Artificial Inorganic Solid Substances, (1964), Academic Press, New York. 